\title{
The numerical study of Pro-autoclaved concrete effect as the thermal bridges Insulation of Residential Building facades and its Effect on Building Heat Transfer Rate Reduction
}

\author{
Muhammad Khalili Azad, Seyed Mahdi Alavian \\ Master student of aerospace engineering, Shiraz University of Technology \\ Member of the Road and Urbanity organization Education Committee, the master expert ofair conditioning
} TRUST company

\begin{abstract}
The outer wall of buildings, are known as the most important portion of building, separating the controlled inner environment from the un-controlled outer environment. In addition to the forming element properties of outer crust, the way of element connection to each other is one of the determiningfactor in energy consuming amount.If these considerations didn't respected, the considerable thermal bridges will be created that can reduce the effect of different elements of crust and increase the heat transfer via the outer crust.In this study, the effect of outer wall thermal bridge insulation by the Pro-autoclave concrete has been surveyed. The insulation of this portion can reduce the outer wall heat transfer about the $56.4 \%$.

Keywords: thermal Bridge, Pro-autoclave concrete
\end{abstract}

\section{Introduction}

Saving in energy consumption is one of the important challenges in the present era.During the recent years, the concern rising about the biologic consequences of energy usage and the global warming have increased the importance of this subject. On the other hand the role of buildings in energy consumption is considerable, therefore during the previous decades in most of improved countries some basic actions have been operated in consumption pattern modification by the various tools such as codification of privacy and regulations. When a wall or surface has not been insulated properly, it may occurred a thermal connection between the inner controlled temperature and outer environment such as the inner space of a building and its outer space.

This connection can be the point of heat leakage or infiltration via the inner space of building toward the outer space. This phenomenon is called thermal bridge. Therefore the thermal bridge is occurred when the surfaces are not be insulated properly and the heat is allowed to transfer via the point that has the lowest thermal resistivity coefficient. The thermal bridges are found at the junctions, metal parts of the building and the locations that has not been insulated appropriately or the insulation materials have the low quality. Insulation of the adjacent surfaces of thermal bridge has no effect on the heat dissipation because the heat finds its way to the open environment via the thermal bridge. The best way is to eliminate the thermal bridge completely. This can be operated by the structural changes of building or the setting of the insulation layers among the junctions or sections with high thermal transfer coefficient. The most known thermal bridges are as below:

- Concrete balconies that are the extra part of the floor base to the out of building, as above and under of them the overall windows are set.

- In commercial structures and niches, the steel parts and portions that are in connection with inner space directly.

- Geometrical thermal bridges such as vertical plate junctions for example the room's corners.

- Metallic connection among the glasses and double glazed walls.

During the building insulation there is an important point that should be considered that the building must be evaluated via the physical and professional principles and high quality insulation materials should be used.ACC is abbreviation of Concrete Aerated Autoclaved that is a concrete product, made of concrete,Silica or silica sand, lime, aluminum powder and water mixture in high pressure and temperature. AAC is classified in light concrete products. Its porous texture made due to bubbling process. This products is presented in the U.S. and Europe via the HEBELEX or YTONG brands.

\section{Material and methods}

In this study the effect of thermal bridges insulation by the AAC on the outer building wall, $3 \times 3.5 \mathrm{~m}^{2}$ dimension, has been assessed in winter situation and constant three dimensional state. 
In this study a given wall with $0.09608 \mathrm{w} / \mathrm{m}^{2} \mathrm{k}$ thermal resistivity in a reinforced concrete framework has been evaluated. After the evaluation of heat transfer amount, the situation has been studied that reinforced concrete framework has been insulated by the wall material, with $0.09608 \mathrm{w} / \mathrm{m} . \mathrm{k}$ thermal resistivity. In this situation the heat transfer decreasing via the insulated reinforced concrete has been surveyed and the effect of wall and insulator size were assessed on the heat transfer decreasing. In the assessing reinforced concrete the 18 $\mathrm{mm}$ wires with $10 \mathrm{~mm}$ three banded stirrup was used. Along the wall one series of stirrup was utilized every 15 $\mathrm{cm}$ that had $5 \mathrm{~cm}$ distance from the concrete surface. As the first sample a framework of reinforced concrete with $30 \mathrm{~cm}$ thick has been evaluated.In the first state the reinforced concrete frame without insulator was assessed. In this situation two different section of reinforced concrete will be evaluated.

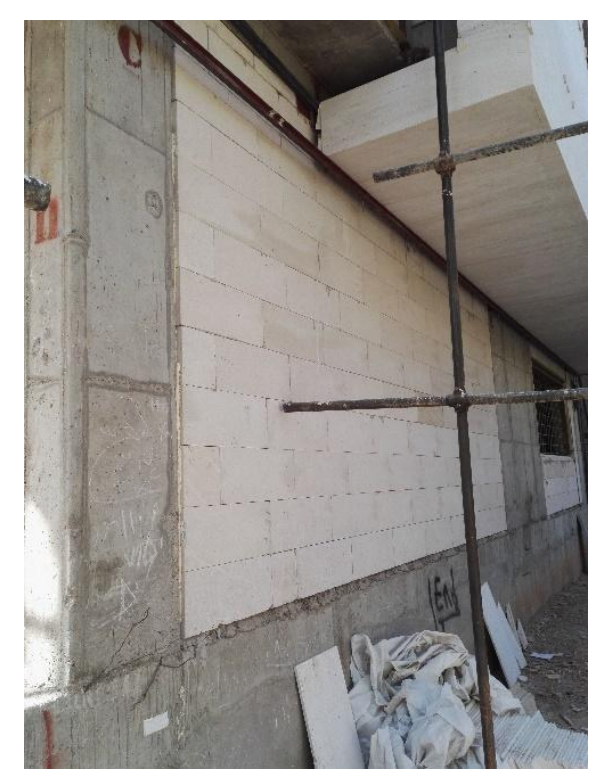

Fig1. Wall with AAC material in a reinforced concrete frame

The section A-A is as below:

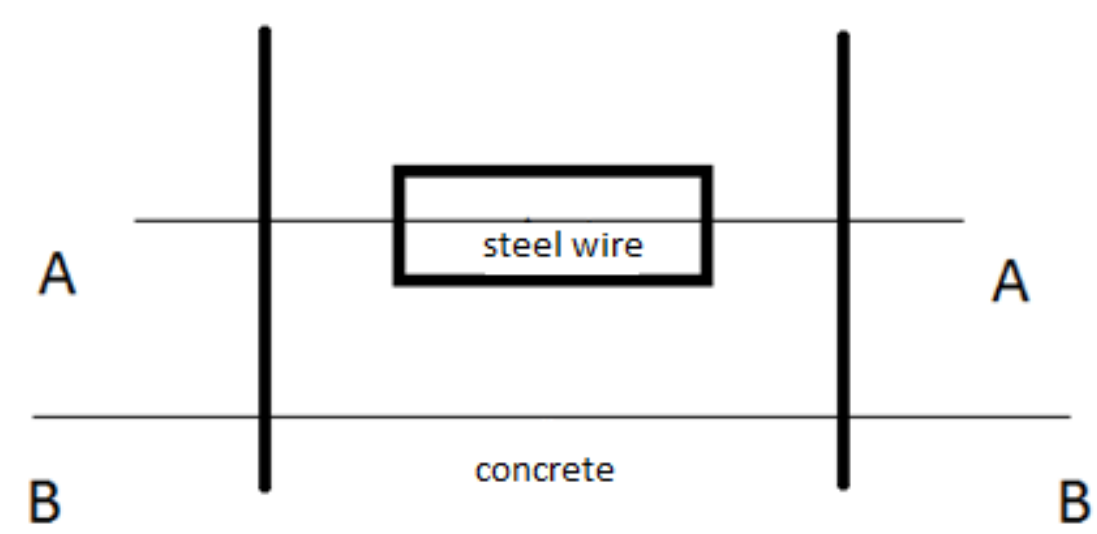

Fig2. Schematic section of study wall

$$
\begin{aligned}
& R=a_{i}+\frac{X_{\text {مفتز }}}{\lambda}+\frac{X_{0}}{\lambda}+a_{O} \\
& R=0.11+\frac{0.2}{50}+\frac{0.1}{2.5}+0.06=0.214 \mathrm{~m} 2 . \mathrm{K} / \mathrm{W} \\
& U_{A-A}=4.67 \mathrm{~W} / \mathrm{m} 2 . K
\end{aligned}
$$

For section B-B:

$R=0.11+\frac{0.3}{2.5}+0.06=0.29 \mathrm{~m} 2 . \mathrm{K} / \mathrm{W}$ 
$U_{B-B}=3.45 \mathrm{~W} / \mathrm{m} 2 . \mathrm{K}$

In a maximum state there should be $4 \%$ wire in reinforced concrete, so:

$U_{\text {reinforced }}$ concrete $=4.67 \times 0.04+3.45 \times 0.96=3.5 \mathrm{~W} / \mathrm{m} 2 . \mathrm{K}$

For the calculating of heat transfer coefficient in a wall with $30 \mathrm{~cm}$ thickness, we have:

$R=0.11+\frac{0.3}{0.0961}+0.06=3.29 \mathrm{~m} 2 . \mathrm{K} / \mathrm{W}$

$U_{W A L L}=0.304 \mathrm{~W} / \mathrm{m} 2 . \mathrm{K}$

For the total heat transfer coefficient, the weight coefficient of wall area onreinforced concrete is used:

$A R E A_{W A L L} \%=\frac{3.2 \times 2.6}{3.8 \times 3.4}=64.4 \%$

$A R E A_{\text {concrete }} \%=100-64.4=35.6 \%$

$U_{\text {All }}=0.644 \times 0.304+0.356 \times 3.5=1.44 \mathrm{~W} / \mathrm{m} 2 . \mathrm{K}$

In the second state: the $5 \mathrm{~cm}$ insulator has been used on the reinforced concrete Section A-A is as below:

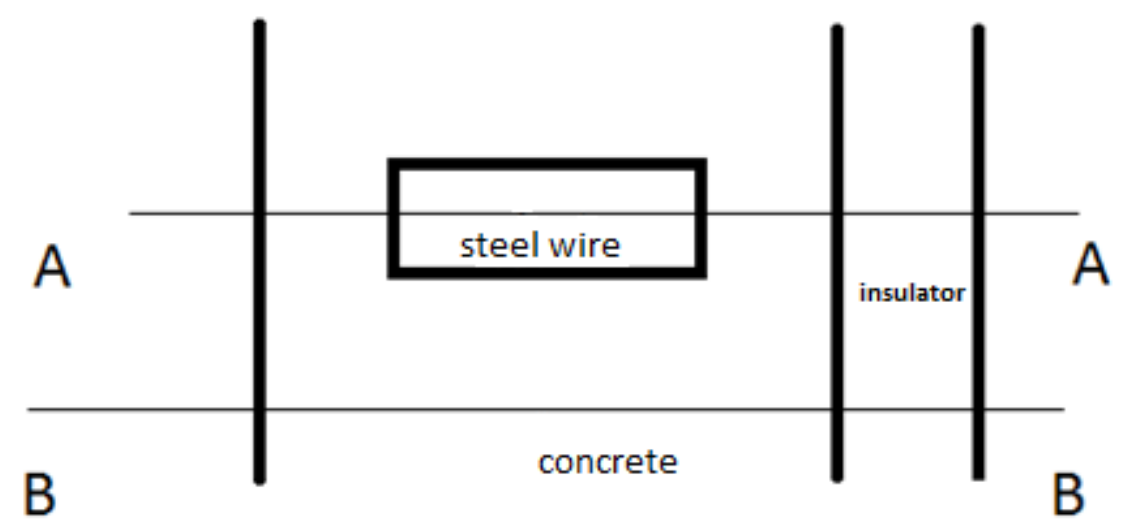

Fig3. Schematic section of study wall.

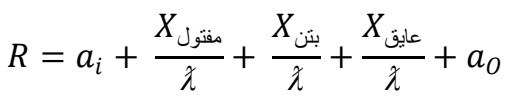

$R=0.11+\frac{0.2}{50}+\frac{0.1}{2.5}+\frac{0.05}{0.0961}+0.06=0.734 \mathrm{~m} 2 . K / W$

$U_{A-A}=1.362 \mathrm{~W} / \mathrm{m} 2 . \mathrm{K}$

For section B-B:

$R=0.11+\frac{0.3}{2.5}+\frac{0.05}{0.0961}+0.06=0.81 \mathrm{~m} 2 . \mathrm{K} / \mathrm{W}$

$U_{B-B}=1.23 \mathrm{~W} / \mathrm{m} 2 . \mathrm{K}$

In a maximum state there should be $4 \%$ wire in reinforced concrete, so:

$U_{\text {reinforced concrete }}=1.362 \times 0.04+1.23 \times 0.96=1.235 \mathrm{~W} / \mathrm{m} 2 . \mathrm{K}$

For the calculating of heat transfer coefficient in a wall with $35 \mathrm{~cm}$ thickness, we have:

$R=0.11+\frac{0.35}{0.0961}+0.06=3.81 \mathrm{~m} 2 . \mathrm{K} / \mathrm{W}$

$U_{W A L L}=0.262 \mathrm{~W} / \mathrm{m} 2 . \mathrm{K}$

For the total heat transfer coefficient, the weight coefficient of wall area onreinforced concrete is used: 
$A R E A_{W A L L} \%=\frac{3.2 \times 2.6}{3.8 \times 3.4}=64.4 \%$

AREA $A_{\text {concrete }} \%=100-64.4=35.6 \%$

$U_{\text {All }}=0.644 \times 0.362+0.356 \times 0.235=0.608 \mathrm{~W} / \mathrm{m} 2 . \mathrm{K}$

$U_{-}$REDUCTION $\%=\frac{(1.44-0.608)}{1.44}=57 \%$

In second analysis an insulated reinforced concrete wall with $20 \mathrm{~cm}$ thickness and $10 \mathrm{~cm}$ middle wire has been used, its results presented in table 1 .

Table1. Obtained decreasing percent and heat transfer coefficient comparison

\begin{tabular}{|c|c|c|c|c|}
\hline $\begin{array}{c}\text { Percent } \\
\text { reduction by } \\
\text { using insulator }\end{array}$ & $\begin{array}{c}\text { Heat transfer coefficient } \\
\text { of 30cm wall }\end{array}$ & $\begin{array}{c}\text { Percent } \\
\text { reduction by } \\
\text { using insulator }\end{array}$ & $\begin{array}{c}\text { Heat transfer coefficient of } \\
\text { 20cm wall }\end{array}$ & material \\
\hline- & 1.44 & - & 1.72 & $\begin{array}{c}\text { Concrete frame } \\
\text { without insulator }\end{array}$ \\
\hline 57 & 0.608 & 60 & 0.695 & $\begin{array}{c}\text { Concrete frame with } \\
5 \mathrm{~cm} \text { insulator }\end{array}$ \\
\hline 71.1 & 0.416 & 72.62 & 0.471 & $\begin{array}{c}\text { Concrete frame with } \\
10 \mathrm{~cm} \text { insulator }\end{array}$ \\
\hline
\end{tabular}

\section{Results}

For an executive playbook upon to the results, it is possible to operate the AAC $5 \mathrm{~cm}$ before the concrete frame. In this situation the $5 \mathrm{~cm}$ distance can be filled by the considered insulator. In this situation the thickness of wall is $20 \mathrm{~cm}$ but the thickness of concrete frame is $25 \mathrm{~cm}$ however the outer part of the wall is completely flat, the wall and concrete frame are tangential.

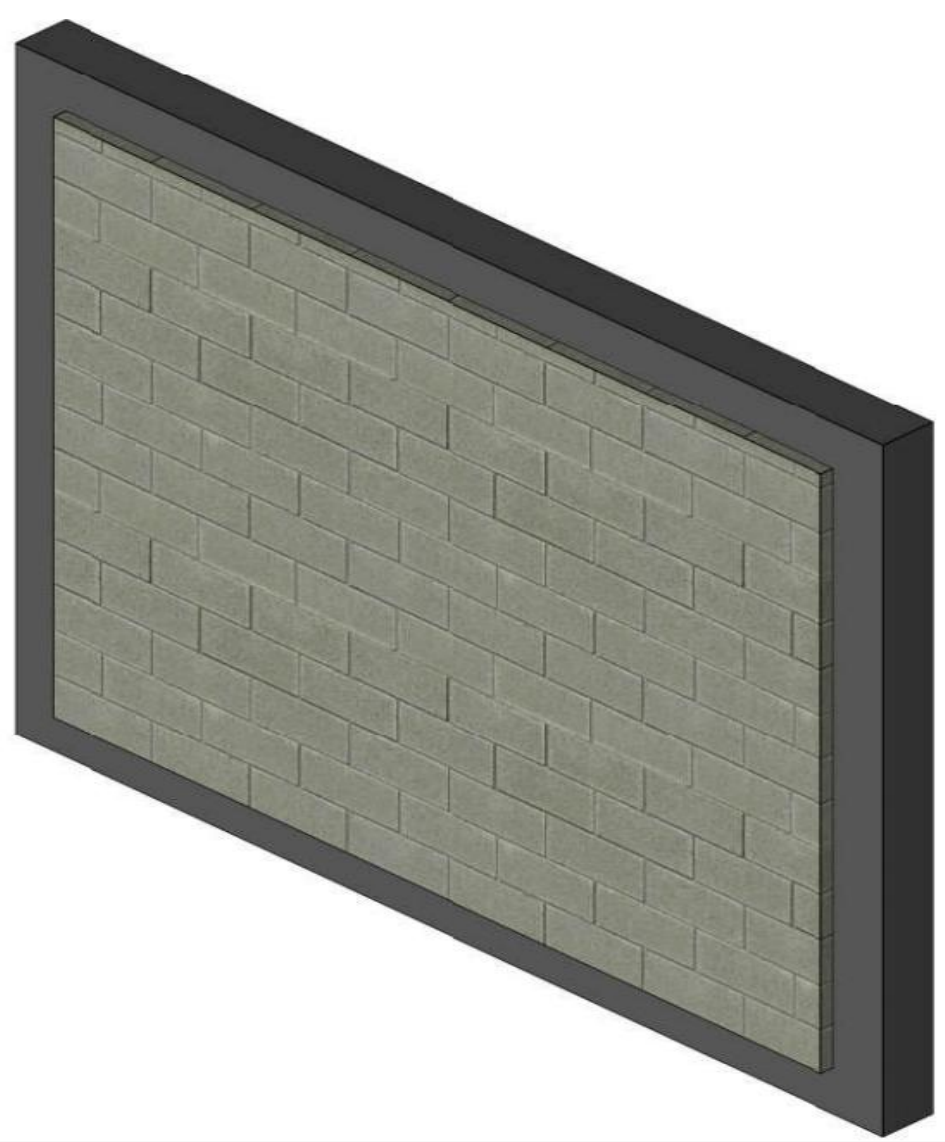

Fig4. Performance steps before the insulation 
Using this operation, the total heat transfer coefficient turned to $0.749 \mathrm{w} / \mathrm{m} 2 \mathrm{k}$ and decreases about the $56.4 \%$ than the without insulation state.

\section{Mathematical relations and equations \\ Conductive heat transfer}

If the local temperature $f$ an object be higher than the other part of it, then the heat currents from the warmer location towards the cold location. This phenomenon is called conductivity.In this situation the heat transfer intermediate is constant so the heat transfer amount is adequate to the heat slope in object and the amount of transferred heat surface. Therefore the conductive heat transfer amount is stated by the Fourieras below:

$$
q=-k A \frac{\partial T}{\partial x}
$$

In the other word the equation 1 states that heat conductivity in an environment depends on geometry, thickness, material type and heat difference.

$$
\begin{array}{r}
\frac{W}{m c^{\circ}} \text { Heat conductivity coefficient: } \mathrm{K} \\
m^{2} \text { Cross section on heat direction: A } \\
C^{\circ} \text { Heat difference: } \Delta \mathrm{T} \\
m \text { Layer thickness: } \Delta \mathrm{x} \\
\frac{J}{S} \text { Transferred heat during the time: } \mathrm{q}
\end{array}
$$

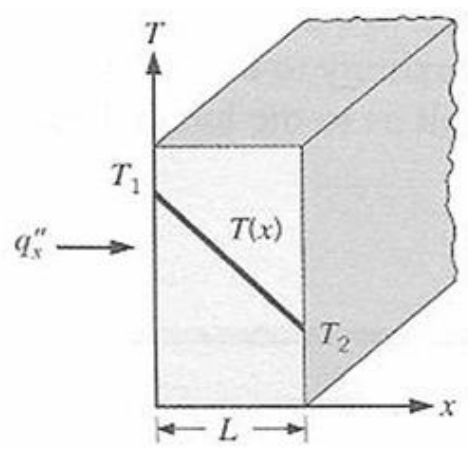

Fig5.one dimensional conductive heat transport

Therefore the Fourier law states the conductive heat transfer mechanism. The negative sign in this law reveals the heat decreasing direction. This law is valid for all states, stable and unstable. Upon to equation 1, if the heat gradient be constant the heat transfer is not a function of thickness because for each thickness the heat transfer amount will be constant.

\section{Heat conductivity coefficient}

Heat conductivity coefficient, is an important heat property of the object that depends on physical situations such as temperature and pressure.So, the bigger heat conductivity coefficient, the object is more conductive and more heat transfer via it and vice versa (Totten, 2008)

\section{Flat wall conductivity coefficient}

Consider a flat wall such as the figure, its one side is nearby the warm fluid (A) and the other side is adjacent to a cold fluid (B), so the heat transfer obtained from the below equation:

$q=h_{1} \mathrm{~A}\left(T_{a}-T_{1}\right)=\frac{K A}{\Delta X}\left(T_{1}-T_{2}\right)=h_{1} \mathrm{~A}\left(T_{2}-T_{b}\right)$ 

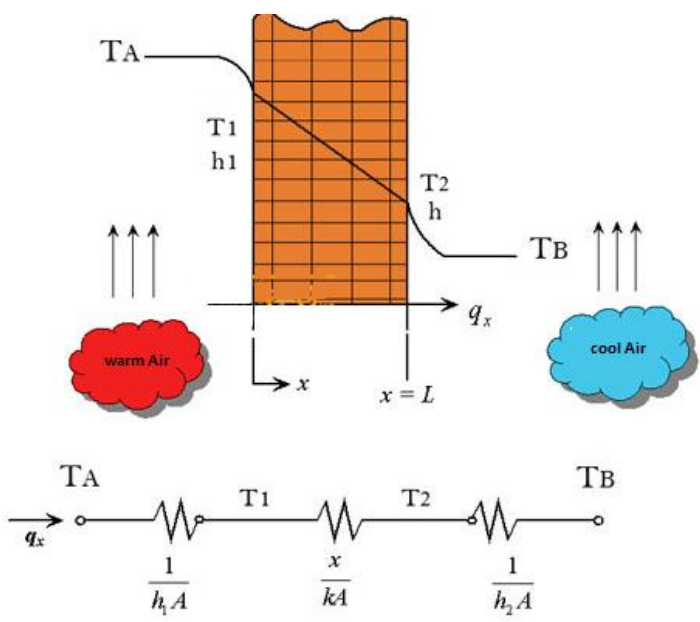

Fig6. Compound heat transfer coefficient calculation

Heat transfer network could be shown by an electrical resistivity network. Total heat transfer calculated as the ratio of total heat difference on the total heat resistivity. $1 / \mathrm{hA}$ is used for the transfer resistivity revealing. Sometimes total heat transfer contains from the conductivity and transfer that stated by $\mathrm{U}$, total heat transfer coefficient, it expressed as below:

$\mathrm{Q}=\mathrm{UA} \Delta \mathrm{T}(4)$

A is the area for the heat current. The total heat transfer on flat wall is as below:

$\mathrm{U}=\frac{1}{\frac{1}{\mathrm{~h}_{1}}+\frac{\Delta \mathrm{x}}{\mathrm{k}}+\frac{1}{\mathrm{~h}_{2}}}(5)$

If the denominator considered as sum of the conductive and transfer resistivity, then:

$R=\frac{1}{h_{1}}+\frac{\Delta x}{k}+\frac{1}{h_{2}}(6)$

\section{Conclusion:}

In this study the effect of thermal bridge insulation by the AAC was evaluated and revealed that this location insulation can decrease the heat transfer via the outer wall.This decreasing is changeable depends on wall thickness. Using a suitable performance the wall heat transfer coefficient can be reduced about the $56.4 \%$.

\section{References:}

[1]. http://www.irima.ir/home/en/thermal-insulation/thermal-extra/thermal-bridge

[2]. http://daghightarh.ir/wp-content/uploads/2015/11/14-CM19-Exer.pdf

[3]. irandanesh.febpco.com/FileEssay/06-CM19-Basic1.pdf

[4]. Totten, Paul E.; O'Brien, Sean M. "The Effects of Thermal Bridging at Interface Conditions". Building Enclosure Science \& Technology. (2008).

[5]. Incorporeal, F.P., and De Witt, D.P., "Fundamentals of Heat and Mass Transfer", John Wiley \& Sons, New York, 1990.

[6]. ASHRAE, ASHRAE Standard 90.1 - "Energy Standard for Buildings except Low-Rise Residential Buildings", ASHRAE.

[7]. Totten, P.E. and Lemieux, D.J., Whole Building Design Guide Federal Building Envelope Design Wall Chapter - Details, National Institute of Building Sciences, 2005.

[8]. http://www.bhrc.ac.ir/nbri/tabid/1232/Default.aspx

[9]. http://www.xella.com/en/content/hebel.php 